\title{
Autologous 4-1BB Selected Tumor Infiltrating Lymphocytes
}

National Cancer Institute

\section{Source}

National Cancer Institute. Autologous 4-1BB Selected Tumor Infiltrating Lymphocytes. NCl Thesaurus. Code C119703.

A preparation of autologous tumor infiltrating lymphocytes (TILs) expressing the costimulatory signaling domain 4-1BB (CD137), with potential antineoplastic activity. TILs are isolated from a patient's tumor and those expressing 4-1BB are selected for expansion in vitro. Upon re-infusion into the patient, the 4-1BB-expressing TILs reinfiltrate the tumor to initiate tumor cell lysis. 4-1BB, a member of the tumor necrosis factor (TNF) receptor superfamily, enhances TIL survival and antitumor cytolytic activity. 